\title{
The Mental Health Impacts of Successive Disasters: Examining the Roles of Individual and Community Resilience Following a Tornado and COVID-19
}

\author{
Jennifer M. First ${ }^{1}\left[\right.$ ] J. Brian Houston ${ }^{2}(1)$ \\ Accepted: 3 December 2021 / Published online: 13 January 2022 \\ (c) The Author(s), under exclusive licence to Springer Science+Business Media, LLC, part of Springer Nature 2021
}

\begin{abstract}
Prior research has found that exposure to natural hazards and infectious disease are associated with adverse mental health outcomes. Less studied are the ways that individual-level and community-level resilience can protect against problematic mental health outcomes following exposure to successive disaster events. In the current study, we examine the role of individual and community resilience on mental health outcomes among 412 adults in Nashville, Tennessee exposed to an EF-3 tornado followed by the COVID-19 pandemic. Results found the cumulative impact of exposure to the tornado and COVID-19 was related to higher levels of PTS and depression symptoms. Individual resilience had a protective, inverse relationship with PTS and depression symptoms and mediated the relationship between community resilience and adverse mental health outcomes. Findings support the development of a multi-system disaster resilience framework that links individual resilience capacities to broader community resilience capacities to activate and sustain healthy adaptation following exposure to successive disasters.
\end{abstract}

Keywords Disasters $\cdot$ COVID-19 $\cdot$ Mental health $\cdot$ Resilience

\section{Introduction}

On the early hours of March 3rd, 2020, the U.S. city of Nashville, Tennessee was hit by an EF-3 nocturnal tornado that killed 25 individuals and injured over 300 (Stanglin et al., 2020). The physical and economic damage from the March 2020 tornado is estimated to be between $\$ 1.5$ and $\$ 2$ billion and was one of the deadliest to affect the Middle Tennessee area (Roach, 2020). Eight days later on March 11, 2020 the World Health Organization declared the coronavirus disease outbreak (COVID-19) a global pandemic. As of May 2021, Tennessee has experienced more than 12,000 COVID-related deaths along with large-scale disruption to its infrastructure, healthcare, employment, education,

Jennifer M. First

jfirst@utk.edu

1 College of Social Work at the University of Tennessee, 420 Henson Hall, Knoxville, TN, USA

2 Department of Communication and Disaster and Community Crisis Center at the University of Missouri, Columbia, USA economies, transportation, and social services (Tennessee Department of Health, 2021).

Decades of research on collective trauma indicates that each of these events in Nashville may independently have adverse mental health impacts for exposed individuals (for a review see Neria et al., 2008). Studies investigating the relationship between disaster exposure and mental health outcomes have reported a dose-response effect, in which posttraumatic stress disorder (PTSD) and depression symptoms are found to increase with greater levels of exposure to a disaster (Brewin et al., 2000; Lowe et al., 2019; Neria et al., 2008; Norris et al., 2002). For example, following a major tornado in Joplin, Missouri, Houston et al. (2015) found having more tornado-related exposure (e.g., property damage, losing a loved one, being displaced, injuries) was related to a greater likelihood of PTSD and depression for participants at both 6 months and 2.5 years following the tornado. Likewise, the global COVID-19 pandemic has the potential to inflict widespread psychological harm with the potential for long-term mental health impacts among exposed individuals (Veldhuis et al., 2021). Studies have found COVID-19-related exposure such as having the virus, being hospitalized with the virus, or having a loved one die from the virus, is 
related to higher rates of adverse mental health (Du et al., 2020; First et al., 2021; Kira et al., 2020; Wu et al., 2020). In addition, facing exposure to both the March 2020 tornado and to the COVID-19 pandemic is likely to be associated with an even greater risk for adverse mental health than to exposure to only one of these disasters. Prior research has examined exposure to multiple disasters via a "cumulative model" wherein exposure to multiple disasters has been found to enhance risk for adverse mental health outcomes (Harville et al., 2017; Jacobs \& Harville, 2015; Lowe et al., 2019). For instance, Lowe et al. (2019) examined the impact of exposure to Hurricane Katrina and the Deepwater Horizon oil spill and found that having exposure to both disasters increased risk for PTSD and depression.

While prior research has examined the negative psychological effects of disasters (i.e. both single and cumulative exposure), limited attention has been given to examining how different system levels of resilience (e.g., individual, family, community, regional) facilitate positive adaptation following cumulative exposure to disaster events. The purpose of the current study is therefore to examine the mental health impact of cumulative exposure to successive disasters, and to explore how individual- and community-level resilience protect against post-disaster PTS and depression symptoms. To begin we review the construct of resilience and consider resilience in terms of individual and community levels.

\section{Individual Disaster Resilience}

A variety of definitions and theoretical perspectives of resilience exist (for a review see Southwick et al., 2014); however, in general human resilience is defined as the capacity of individuals or systems to adapt positively to challenges that threaten their survival or functioning (Masten, 2001). To examine the human process of adaption, resilience research considers risk exposure, protective factors, and outcomes. For example, when an individual encounters a disaster event, resilience can be understood to be the combination of risk factors (e.g., things that exacerbate or worsen outcomes) and various protective factors (e.g., things that ameliorate negative outcomes) that emanate from human systems (e.g., individual, family, community). These protective factors foster the adaptation processes and influence positive outcomes (e.g., mental health, wellness, development) in the midst of risk (Bonanno et al., 2004; Masten, 2001; Ungar, 2013).

In the context of disaster, multiple studies have found individual-level resilience to have an inverse relationship with adverse mental health outcomes (Ahmad et al., 2010; Bistricky et al., 2019; Bonanno et al., 2006; Fereirre et al., 2019; Long et al., 2020; Ying et al., 2014). For instance, Osofsky et al. (2011) found that internal traits of resilience (i.e., self-efficacy) were associated with less depression and anxiety in a sample exposed to Hurricane Katrina and the Deepwater Horizon oil spill. At the individual level, both internal and external protective factors have been found to facilitate resilience following disaster events. Examples of internal factors include adaptive coping strategies such as distress regulation, problem solving, and optimism (Luther et al., 2000; Masten, 2001). Internal factors often help individuals regulate emotions, work toward goals, and maintain healthy connections. In addition to internal factors, individuals draw from the external resources in their environment that further support their successful adaptation and wellbeing. For example, external resources may include having access to material goods (e.g., finances, housing, transportation), interpersonal relationships (e.g., family, friends), and community supports (e.g., social services) that assist individuals in positive adaption following disaster adversity (Houston et al., 2017; Norris et al., 2008).

Individual disaster resilience is thus the combination of internal and external resources that help an individual adapt following a challenging event like a disaster. Overall, many of the resources that foster individual resilience come from social and community systems (Ungar et al., 2013). For example, supportive interpersonal relationships that promote resilience in disaster situations (e.g., emotional support, child care, information) are often accessed via an individual's social network (Aldrich \& Meyer, 2015). Additionally, even many of the internal resources that foster resilience in individuals have origins in social and community systems (Abramson, et al., 2015; Masten \& Obradovic, 2008). For instance, self-efficacy, a previously described internal factor that fosters resilience post-disaster (Osofsky et al., 2011), is an internal capacity of an individual, but is likely dependent upon an individual having resources like a supportive family structure or helpful educational opportunities. Thus, while conceptualized as an individual-level construct, individual disaster resilience is highly dependent on accessing resources and supports outside of the individual (First et al., 2021).

\section{Community Disaster Resilience}

In addition to individual resilience, community resilience is important in fostering human adaptation following a disaster. Community resilience is a process linking a set of adaptive capacities to a positive trajectory of community functioning and adaptation after a disturbance (i.e., natural and human-caused disasters, public health emergencies; Norris et al., 2008). A resilient community is more than simply a collection of resilient individuals, but is instead a community that can work collectively to ensure the people across the community are able to adapt following a disaster (Houston et al., 2015). Community disaster resilience has been conceptualized as a 
multidimensional construct representing the abilities of local community to operate as a complex system (e.g., critical infrastructures, agencies, natural and built environments, and citizens) and adapt to collective adversity (Norris et al., 2008). Pfefferbaum et al (2013) proposed four core components of adaptive capacity for communities in the face of disasters and public health hazards: connection and caring, resources, transformative potential, and disaster management. Following disasters, community resilience has been linked to better individual mental health outcomes. For instance, Fullerton et al. (2015) found that community-level factors of collective efficacy mitigated the impact of hurricanes in Florida on depression symptoms. Likewise, following a major flood in England, Wind and Komproe (2012) found higher social capital and collective efficacy was related to less posttraumatic stress symptoms.

Taken together, a consistent finding across the literature is that human resilience is a process of harnessing multiple protective mechanisms in an individual's environment (e.g., individual, community, nation) to foster healthy adaptation despite adversity. While prior studies have supported the protective effects of individual and community resilience in disaster contexts, much of the research has examined these two systems in isolation, with limited focus of their additive contributions and mechanisms linked to better mental health outcomes. To address this gap, our study objectives included examining (a) how cumulative exposure to the Nashville tornado and COVID-19 pandemic impact mental health outcomes (e.g., PTS and depression symptoms), and (b) how the relationships between community and individual resilience impact mental health outcomes. We used structural equation modeling (SEM) to develop and test hypothesized pathways between cumulative disaster exposure, individual and community resilience, and PTS and depression symptoms. Based on the evidence reviewed above, we propose the following hypotheses to guide this study:

H1 More cumulative exposure to the tornado and COVID19 will be associated with higher levels of PTS and depressive symptoms.

H2 Individual resilience will be inversely related with PTS and depression symptoms.

H3 Community resilience will be inversely related with PTS and depression symptoms.

H4 Individual resilience will mediate the relationship between community resilience and PTS and depression symptoms.

\section{Method}

In order to test our proposed hypotheses, we conducted an online survey with 412 adults (18 years or older) living in Nashville, Tennessee. Data were collected in February 2021, approximately one year following the March 3, 2020 EF-3 tornado and one year into the COVID-19 pandemic.

\section{Participants and Procedures}

Data collection procedures were approved by the [identity removed for review] Institutional Review Board (IRB). Participants were recruited through a partnership with a local volunteer organization who managed the volunteer recovery efforts following both the tornado and COVID-19 pandemic. Potential respondents were invited to complete the survey via social media posts and email. Interested participants used a secure URL to review the study's purpose and access the survey. An electronic informed consent indicated that participation was voluntary and responses would be anonymous. After consenting to the study, participants began the online survey. Participants were eligible to enter a prize drawing to receive one of four $\$ 50$ gift cards as an incentive. At the end of the survey, participants were provided with a list of local community resources for tornado and COVID-19 relief.

Of the 412 participants, 313 were female $(75.9 \%)$ and 95 were male $(23.1 \%)$. A majority of participants identified as White/Caucasian ( $n=301,73.0 \%)$, followed by Black $(n=45,10.9 \%)$, Native American $(n=24,5.8 \%)$, Asian $(n=20,4.9 \%)$, Hispanic/Latino $(n=16,3.9 \%)$, Native Hawaiian/Pacific Islander $(n=3,0.7 \%)$, and multiracial $(n=2,0.5 \%)$. The age of participants ranged from 18 to 75 years and older, with $18-24$ years old at $8.0 \%$ $(n=33), 25-34$ years old at $46.6 \%(n=192), 35-44$ years old at $21.6 \%(n=89), 45-54$ years old at $9.2 \%(n=38)$, 55-64 years old at 9.2\% $(n=38), 65-74$ years old at $4.1 \%$ $(n=17)$, and 75 years or older at $1.0 \%(n=4)$. Over half of all participants had full time employment $64.8 \%(n=267)$ and the majority of participants had a bachelor's degree or higher $(n=307,74.5 \%)$. See Table 1 for descriptive statistics of participant demographics.

\section{Measures}

\section{Cumulative Disaster Exposure}

We assessed tornado and COVID-19 exposure by asking participants about their experiences related to each event. For tornado exposure we asked participants if they experienced: (1) injury to oneself or to a loved one, (2) property damage, (3) or believed they or someone they knew would 
Table 1 Descriptive information on participants

\begin{tabular}{|c|c|c|}
\hline & $N$ & $\%$ \\
\hline \multicolumn{3}{|l|}{ Gender } \\
\hline Male & 95 & 23.1 \\
\hline Female & 313 & 75.9 \\
\hline \multicolumn{3}{|l|}{ Race } \\
\hline American Indian/Alaskan Native & 24 & 5.8 \\
\hline Black/African American/Afro-Caribbean & 45 & 10.9 \\
\hline Asian American & 2 & 4.9 \\
\hline Hispanic/Latino & 16 & 3.9 \\
\hline White & 301 & 73.0 \\
\hline Multi-racial & 2 & 0.5 \\
\hline \multicolumn{3}{|l|}{ Age } \\
\hline $18-24$ & 33 & 8.0 \\
\hline $25-34$ & 192 & 46.6 \\
\hline $35-44$ & 89 & 21.6 \\
\hline $45-54$ & 38 & 9.2 \\
\hline $55-64$ & 38 & 9.2 \\
\hline $65-74$ & 17 & 4.1 \\
\hline 75 and older & 4 & 1.0 \\
\hline \multicolumn{3}{|l|}{ Income } \\
\hline Less than $\$ 15,000$ & 16 & 3.9 \\
\hline$\$ 15,000$ to $\$ 29,999$ & 37 & 9.0 \\
\hline$\$ 30,000$ to $\$ 44,999$ & 67 & 16.3 \\
\hline$\$ 45,000$ to $\$ 59,999$ & 69 & 16.7 \\
\hline$\$ 60,000$ to $\$ 74,999$ & 55 & 13.3 \\
\hline$\$ 75,000$ to $\$ 104,999$ & 73 & 17.7 \\
\hline$\$ 105,000$ or more & 90 & 21.8 \\
\hline \multicolumn{3}{|l|}{ Education } \\
\hline Grade school & 2 & 0.5 \\
\hline Some high school & 11 & 2.7 \\
\hline High school graduate & 17 & 4.1 \\
\hline Some college & 73 & 17.7 \\
\hline College graduate & 189 & 45.9 \\
\hline Advanced degree & 118 & 28.6 \\
\hline \multicolumn{3}{|l|}{ Cumulative disaster exposure } \\
\hline Neither Tornado and COVID-19 & 37 & 9.0 \\
\hline Either Tornado and COVID-19 & 195 & 47.3 \\
\hline Both Tornado or COVID-19 & 177 & 43.0 \\
\hline
\end{tabular}

be killed or harmed by the tornado. For COVID-19 exposure we asked participants: (1) if they had the coronavirus, (2) if someone in their family or household had the coronavirus, or (3) if they had financial hardship related to COVID19. Response options for each experience were 1 (yes) or 0 (no). These tornado (Demuth, 2018; Houston et al., 2015) and COVID-19 exposure items (Du et al., 2020; First et al., 2020) have been found to be associated with adverse mental health outcomes.

For analysis, we considered anyone who responded yes to at least one of the tornado or COVID-19 experience items included in our assessment to have exposure to that event. We then summed the tornado and COVID-19 exposures to yield a cumulative disaster exposure index that classified participants as having been exposed to neither disaster (0), only one of the two disasters (tornado or COVID-19; 1), or both disasters (2). Higher scores indicated greater cumulative effects.

\section{Individual Resilience}

Individual disaster resilience $(M=129.04, S D=25.51)$ was measured via the Disaster Adaptation and Resilience Scale (DARS; First et al., 2021), a 43-item multidimensional scale designed to measure internal and external factors supporting individual resilience in disaster contexts. DARS consists of five domains found to support individual resilience, including: material resources, social resources, distress regulation, problem-solving, and optimism. Sample items include "I have stable or permanent housing" (material resources); "I have people I can turn to and ask for help" (social resources); "I give myself time to recover from upsetting situations" (distress regulation); "I look for information or resources to help deal with challenges" (problem-solving); and "I believe I will make it through difficult times" (optimism). Each item is rated on a 5- point Likert scale ranging from 0 (not at all true) to 4 (true nearly all of the time), with higher scores reflecting higher levels of resilience. In the present sample, the Cronbach's alpha value was 0.96 .

\section{Community Resilience}

Community resilience $(M=69.32, S D=12.25)$ was measured via the Communities Advancing Resilience Toolkit (CART; Pfefferbaum et al., 2013), a 21-item multidimensional scale that assesses perceptions of community resilience to disaster events with four constructs: connection and caring; community resources; transformative potential; and disaster management. Sample items: "People in my community (i.e., Nashville) help each other" (connection and caring), "My community (i.e., Nashville) has resources (e.g., money, information, technology, tools, raw materials, and services) it needs to take care of community problems (community resources), "People in my community (i.e., Nashville) communicate with leaders who can help improve the community" (transformative potential), and "My community (i.e., Nashville) can provide emergency services during a disaster" (disaster management). Each item is scored on a 5-point Likert scale from 1 (strongly disagree) to 5 (strongly agree), with higher scores reflecting higher levels of community resilience. In the present sample, the Cronbach's alpha value was 0.93 . 


\section{Posttraumatic Stress}

Posttraumatic stress symptoms $(M=40.62, S D=16.05)$ were measured with the Posttraumatic Stress Disorder Checklist for Civilians (PCL-C; Blevins, Weather, Davis, Witte, Domino, 2015), a 17-item self-report questionnaire that assesses for probable PTSD diagnosis in individuals exposed to a traumatic event. The PCL-C has four subscales, including re-experiencing symptoms, avoidance symptoms, negative alterations in cognition and mood and arousal symptoms. Each item is scored on a five-point Likert scale ranging from not at all (1) to extremely (5). Respondents were asked to indicate how often they were bothered by each of the symptoms during the past month. In the present sample, the Cronbach's alpha value was 0.95 .

\section{Depression}

Symptoms of depression $(M=9.80, S D=6.58)$ were assessed with the Patient Health Questionnaire-9 (PHQ9; Kroenke et al., 2001). The PHQ measures the degree to which an individual has experienced depressed mood and anhedonia over the past 2 weeks in order to screen participants for depression. Respondents were asked to indicate how often they were bothered by each symptom using four response options ranging from not at all (0) to nearly every day (3), and whether the symptoms endorsed occurred within the same two-week period. In the present sample, the Cronbach's alpha value was 0.91 .

\section{Analysis}

Data analysis was conducted using $\mathrm{R}$ statistical software and packages (R Development Core Team, 2011). Demographic characteristics of respondents were analyzed using univariate methods including means, standard deviations, frequencies, and percentages as appropriate. To examine the relationships between cumulative disaster exposure, individual and community resilience, and mental health outcomes, we used structural equation modeling (SEM) with a robust maximum likelihood estimation to ensure multivariate normality. Using a two-step procedure recommended by Kline (2015), we first tested a measurement model (confirmatory factor analysis, CFA) to examine and confirm the factor structure of the latent variables and indicators (e.g., individual resilience, community resilience, depression, PTS). To obtain standardized, unit-free estimates that reflect the indicator reliabilities, we set the scale using the fixed factor method, which sets the latent variance to one (e.g., $\psi=1.0$ ). For missing data, a full information maximum likelihood estimation was implemented, which assumes missing data points have an expectation equal to a model-derived value that is estimated from the remaining data points (Cham et al.,
2017). We used Little's (2013) guidelines for goodness of fit indices, including root mean square error of approximation (RMSEA; values of 0.08 or less indicate adequate fit), standardized root mean square residual (SRMR; values of 0.08 or less indicate adequate fit), Tucker-Lewis index (TLI; which should be equal to, or greater than, 0.90), and comparative fit index (CFI; which should be equal to, or greater than, 0.90). After establishing the measurement model, we estimated a structural model to examine how risk and protective factors were associated with mental health outcomes. The indirect effects were tested by inspecting the $95 \%$ confidence interval of 1,000 bootstrapped resamples of the product of coefficients to ensure the confidence intervals do not include zero, and therefore the effect is considered statistically significant (Preacher \& Hayes, 2008).

\section{Results}

Descriptive statistics for cumulative disaster exposure and demographics are provided in Table 1. As shown, 9\% of participants were exposed to neither the tornado or COVID$19,47.3 \%$ were exposed to either the tornado or COVID-19, and $43 \%$ were exposure to both the tornado and COVID-19. To examine the relationships between risk (i.e., cumulative disaster exposure) and resilience factors (i.e., individual and community) on mental health outcomes, we used structural equation modeling (SEM). Our initial SEM measurement model converged; however, it revealed unacceptable levels of fit (i.e., both CFI and TLI were less than 0.90) due to a high number of indicators (43 items) for the individual resilience latent variable and the community resilience latent variable (21 items). To remedy this problem, the 43 individual disaster resilience items were fit into five parcels so that each parcel formed a theoretically meaningful cluster related to the five factors of the scale (Little et al., 2013). Likewise, the 21 community resilience items were then parceled or subdivided into four parcels related to the four factors of the scale to ensure a similar spread of itemtotal correlations' size (Little, et al., 2013). The individual resilience parcels showed acceptable to high factor loadings $(0.58-0.93)$ on the latent variable and the community resilience parcels showed acceptable to high factor loadings (0.72-0.91), indicating they represented the latent variables well. After parceling the measurement model exhibited acceptable fit with the data and the model fit statistics were: $\chi^{2}(891)=2116.78, p<0.01 ; \mathrm{CFI}=0.91 ; \mathrm{TLI}=0.90$; $\mathrm{RMSEA}=0.06 ; \mathrm{SRMR}=0.08$. After establishing the measurement model, we estimated the structural relationships between the observed and latent variables. The structural model achieved acceptable fit, model fit statistics included $\chi^{2}(1007)=2201.258, \mathrm{p}<0.01, \mathrm{CFI}=0.90, \mathrm{TLI}=0.90$, $\mathrm{RMSEA}=0.06, \mathrm{SRMR}=0.08$, and allowed for the testing 
Table 2 Structural model: regression paths

\begin{tabular}{|c|c|c|c|}
\hline Regression paths & $\begin{array}{l}\text { Unstandardized } \\
\text { estimate }\end{array}$ & Standard error & Standard estimate \\
\hline \multicolumn{4}{|l|}{ Individual resilience $\left(\mathrm{R}^{2}=0.43\right)$} \\
\hline Community resilience & 0.621 & 0.098 & $0.469 * * *$ \\
\hline \multicolumn{4}{|l|}{ Posttraumatic stress $\left(\mathrm{R}^{2}=0.41\right)$} \\
\hline Cumulative disaster exposure & 0.194 & 0.033 & $0.277 * * *$ \\
\hline Individual resilience & -0.467 & 0.089 & $-0.477 * * *$ \\
\hline Community resilience & 0.021 & 0.032 & 0.016 \\
\hline \multicolumn{4}{|l|}{ Depression $\left(\mathrm{R}^{2}=0.36\right)$} \\
\hline Cumulative disaster exposure & 0.121 & 0.033 & $0.179 * * *$ \\
\hline Individual resilience & -0.489 & 0.089 & $-0.519 * * *$ \\
\hline Community resilience & 0.042 & 0.073 & 0.034 \\
\hline
\end{tabular}

Model Fit statistics: $\chi^{2}(1007)=2201.258, p<0.01$, CFI $=0.90$, TLI $=0.90$, RMSEA $=0.06$, SRMR $=0.08$. Covariates: Gender and Income, ${ }^{*} p<0.05,{ }^{* *} p<0.01, * * * p<0.001$
Fig. 1 Diagram of structural model

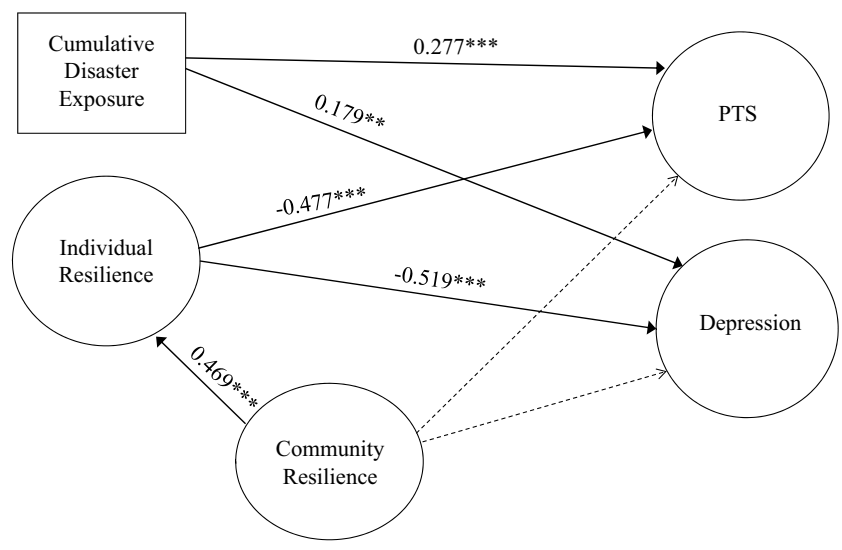

Note: Model Fit statistics: $\chi 2(1007)=2201.258, \mathrm{p}<.01, \mathrm{CFI}=.90, \mathrm{TLI}=0.90, \mathrm{RMSEA}=0.06, \mathrm{SRMR}=0.08$. Covariates: Gender and Income. PTS $=$ Posttraumatic stress symptoms. Bold lines indicate statistically significant. ${ }^{*} p<.05,{ }^{* *} p<.01,{ }^{* * *} p<.001$. of our hypotheses. See Table 2 and Fig. 1 for a diagram of the structural results.

Our first hypothesis (H1) predicted that cumulative disaster exposure would have a significant positive relationship with PTS and depression symptoms. H1 was supported, as we found cumulative disaster exposure had a significant and positive relationship between PTS $(\beta=0.277$, $p<0.001)$ and depression $(\beta=0.179, p<0.001)$. Next, our second hypothesis $(\mathrm{H} 2)$ predicted that individual resilience would be inversely associated with PTS and depression symptoms. H2 was supported as results found that individual resilience was significantly associated with having less PTS $(\beta=-0.477, p<0.001)$ and depression symptoms $(\beta=-0.519, p<0.001)$. Our third hypothesis $(\mathrm{H} 3)$ predicted that community resilience indicators would be inversely associated with PTS and depression symptoms. However, H3 was not supported as community resilience did not have a significant association with PTS and depression symptoms. Rather, as predicted in our fourth hypothesis
(H4), community resilience was indirectly related to mental health outcomes through individual disaster resilience, and was found to be related to less PTSD $(\beta=-0.244, p<0.01$, [CI 95\%-0.484, -0.217]) and depression symptoms $(\beta=-0.224, p<0.01$, [CI 95\%: $-0.460,-0.206])$ based on the $95 \%$ confidence interval from 1000 bootstrapped resamples.

\section{Discussion}

While disaster research has extensively studied risk factors impacting adverse mental health, there is growing literature supporting the role of various resilience mechanisms in supporting mental health outcomes. Prior studies have supported the protective effects of individual and community resilience in disaster contexts, however much of the research has examined these two systems in isolation, thus potentially overlooking their potentially synergistic effects for better 
mental health outcomes. In the current study we examined the capacity of individual and community resilience dimensions to support mental health outcomes among individuals exposed to successive disasters. Our results point to several main findings.

First, our study's findings demonstrate that both exposure to the tornado (i.e., injury to oneself or to a loved one, property damage, or believed they or someone they knew would be killed or harmed by the tornado) and exposure related to COVID-19 (e.g., being infected, family members being infected, or financial hardship related to COVID-19) were associated with higher levels of depression and PTS symptoms. This finding highlights the potentially harmful consequences of cumulative exposure to both natural hazards and pandemics, suggesting that these events can have an adverse cumulative impact on mental health. This finding is consistent with previous studies (Garfin et al., 2015: Harville et al., 2017; Jacobs \& Harville, 2015; Lowe et al., 2019) that have illustrated the phenomenon of cumulative exposure as being predicted by more exposure to collective trauma (e.g., multiple hurricanes, oil spill, bombing), which may predispose people to more adverse mental health. In terms of implications, screening for exposure to multiple collective traumas (e.g., natural hazards, COVID-19 pandemic) may help clinicians identify individuals who are at greater risk for adverse mental health problems.

In the context of cumulative disaster exposure, it is also important to note that the community of Nashville encountered a third disaster event that was not captured in the current study. On December 25, 2020, a recreational vehicle detonated explosives in downtown Nashville which caused major destruction to the AT\&T building and neighboring buildings, and injured three people (Krusi, 2021). Given the magnitude of the destruction and the media coverage surrounding the explosion, it may have further compounded PTS and depression symptoms among the study's respondents. While we were not able to capture exposure to the bombing, given the timing of our data collection (February 2021) our resilience findings provide important insights into individual and community-level protective factors that were associated with lower levels of PTS and depression symptoms for respondents.

In regards to insights into resilience, first, we found that individual-level resilience, consisting of internal adaptive coping strategies, as well as external physical resources and supportive relationships, served a protective function and was associated with lower levels of PTS and depression symptoms. The measure we used in the current study was adapted specifically for use related to individual resilience following disasters (First et al., 2021), and it assessed both internal and external protective resources. This approach is distinct from most previous disaster resilience studies (Ahmad et al., 2010; Irmansyah et al., 2010; Ying et al.,
2014), which employed a general assessment of resilience comprised primarily of psychological facets or individual personality traits (Windle et al., 2011). While general measures of individual resilience are useful in capturing personality traits associated with resilience, internal traits represent just a portion of adaptive capacities available to an individual (Hobfoll, 2015). This work builds upon prior studies that have highlighted the importance of external resources being available in the disaster context in order to facilitate individual resilience and contribute to better mental health outcomes (Abramson, et al., 2015; Bonanno et al., 2006; Fereirre et al., 2019; Hobfoll, 2015).

Second, we found that community-level resilience consisting of indicators measuring a community's ability to foster connection and caring, community resources, transformative potential, and disaster management, was not directly related to decreasing PTS and depression symptoms. Rather, capacities supporting community resilience (e.g., community connections, resources, transformative potential, and disaster management) were found to increase individual resilience (e.g., physical, social, and psychological resources), which in turn reduced adverse mental health outcomes in respondents. Prior studies have highlighted the importance of community-level factors in supporting positive outcomes in disaster contexts (Fullerton et al., 2015; Gelkoph et al., 2012; Lowe et al., 2015), and this study further illustrates the mechanisms or processes that underlie the distinctive functioning of individual-level and community-level resilience working in tandem in reducing adverse mental health outcomes. As demonstrated in the current study, enhancing individual resilience requires enhancing community resilience and therefore both are critical factors in mitigating a disaster's impact on mental health outcomes.

In terms of implications, these findings could be used to inform recommendations for clinicians and policymakers about individual and community-level capacities to target for interventions to support mental health following successive disasters. In addition, findings from the current study support the development of a multi-system framework that integrates individual resilience capacities with broader community resilience activities to foster multiple adaptive pathways and sustaining healthy adaptation over the long-term. Disasters resulting from natural hazards and disease outbreaks are multi-systemic and therefore would benefit from an integrated systems perspective to capture the multiple adaptive capacities that support positive outcomes (Masten $\&$ Motti-Stefanidi, 2020). We believe the social work profession provides a unique professional lens for the development of a multi-system disaster resilience framework that seeks to activate and sustain healthy adaptation following exposure to successive disasters. Utilizing the current study's findings, Table 3 illustrates how community capacities and individual capacities could align and how social work strategies 
Table 3 Multi-system disaster resilience: a framework for social work

\begin{tabular}{|c|c|c|c|c|}
\hline \multicolumn{2}{|l|}{ Individual resilience $^{\mathrm{a}}$} & \multicolumn{2}{|l|}{ Community resilience $^{\mathrm{b}}$} & \multirow{2}{*}{$\begin{array}{l}\text { Social work } \\
\text { Strategies to increase capaci- } \\
\text { ties }\end{array}$} \\
\hline Individual capacities & Description & Community capacities & Description & \\
\hline Material resources & $\begin{array}{l}\text { Access to economic, mate- } \\
\text { rial, and health resources }\end{array}$ & Community resources & $\begin{array}{l}\text { Community programs and } \\
\text { resources to help com- } \\
\text { munity members }\end{array}$ & $\begin{array}{l}\text { Mobilize material resources } \\
\text { Connect survivors to com- } \\
\text { munity resources } \\
\text { Advocate for policies that } \\
\text { eliminate inequalities in } \\
\text { access to resources }\end{array}$ \\
\hline Social capital & $\begin{array}{l}\text { Having social support and } \\
\text { community connections }\end{array}$ & Connection and Caring & $\begin{array}{l}\text { Belonging in community, } \\
\text { community members help } \\
\text { each other }\end{array}$ & $\begin{array}{l}\text { Develop social support } \\
\text { groups } \\
\text { Foster social networks and } \\
\text { community connections } \\
\text { (e.g., volunteerism, commu- } \\
\text { nity development projects) }\end{array}$ \\
\hline Adaptive coping skills & $\begin{array}{l}\text { Coping skills including } \\
\text { problem solving, opti- } \\
\text { mism, distress regulation }\end{array}$ & Transformative Potential & $\begin{array}{l}\text { Ability of community to } \\
\text { problem solve and learn } \\
\text { from past }\end{array}$ & $\begin{array}{l}\text { Provide education and tools } \\
\text { on adaptive coping skills } \\
\text { Collaborate with community } \\
\text { advocacy groups to trans- } \\
\text { form social problems and } \\
\text { inequalities }\end{array}$ \\
\hline \multirow[t]{2}{*}{ Preparedness } & \multirow[t]{2}{*}{$\begin{array}{l}\text { Prepared and informed on } \\
\text { disasters and emergencies }\end{array}$} & Disaster Management & $\begin{array}{l}\text { Community prepares and } \\
\text { responds to disasters and } \\
\text { emergencies }\end{array}$ & \multirow{2}{*}{$\begin{array}{l}\text { Provide education on disaster } \\
\text { preparedness } \\
\text { Identify disaster communica- } \\
\text { tion tools and resources }\end{array}$} \\
\hline & & $\begin{array}{l}\text { Information/Communica- } \\
\text { tion }\end{array}$ & $\begin{array}{l}\text { Community keeps people } \\
\text { informed }\end{array}$ & \\
\hline
\end{tabular}

The first two columns include capacities for individual and community resilience. Parallel capacities are shown on the same rows. The final column shows social work strategies to increase capacities for individual and community resilience

${ }^{\mathrm{a} D i s a s t e r}$ Adaptation and Resilience Scale (DARS, First et al., 2021)

${ }^{\mathrm{b}}$ Communities Advancing Resilience Tool (CART; Pfefferbaum et al., 2015)

could increase capacities at both levels from a multi-system perspective. Social workers have the ability to work across micro and macro levels of practice and possess a range of skills and competencies including resource allocation, systems navigation, community development, policy advocacy, group support, crisis management, and communication tools (Ascroft et al., 2018; Bauwens \& Natural, 2017; WalterMcCabe, 2020).

\section{Limitations}

The results from this study should be interpreted in light of its limitations. First, as mentioned previously, assessment of participants' exposure to the December 2020 bombing in Nashville was not captured in this study. As such, omitting the assessment of potential exposure to the bombing may have led to an underestimation of the influence of cumulative exposure on mental health outcomes. Second, this study utilized an online questionnaire which required internet access and may have limited participation among those with lower incomes, less education, and of older age. Third, the majority of our participants identified as female and white. Future research should replicate this work with more racially and ethnically diverse sample. Fourth, community resilience was measured by participant's perceptions of their community. Future community resilience research would benefit from incorporating geographical and physical indicators of community-level factors supporting resilience. Lastly, this study was cross-sectional in design and therefore the collected data precludes causal claims of temporal order (Maxwell \& Cole, 2007). However, the present study presents a model that is grounded in the theoretical literature and was supported by previous research investigations (First et al., 2020, 2021; Masten \& Obradovic, 2008; Pfefferbaum et al., 2015), all of which provide a compelling case for investigating the direct and indirect relationships we conducted in the current study. Future research could improve on this limitation and employ a longitudinal design that collects data at several points in time. Despite these limitations, this study takes an important step towards identifying and testing individual and community capacities to identify how they contribute to better mental health outcomes following successive disaster events. 


\section{Conclusion}

In the current study we used structural equation modeling (SEM) to identify the relationships between risk (i.e., cumulative disaster exposure) and resilience factors (i.e., individual and community) on mental health outcomes following successive disasters of an EF-3 tornado and the COVID19 pandemic in a sample of 412 residents from Nashville Tennessee. We found that cumulative disaster exposure to both the tornado and COVID-19 was significantly related to higher levels of PTS and depression symptoms. Individual resilience was inversely related to PTS and depression symptoms and played an important role in mediating the relationship between community resilience and mental health outcomes. Findings from this study informed the development of a multi-system disaster resilience framework for social work that links individual resilience capacities to broader community resilience capacities to foster multiple adaptive pathways following successive disaster events.

Acknowledgements The authors wish to thank the organization Hands on Nashville for their assistance with recruitment and data collection.

Funding This research received no external funding.

\section{Declarations}

Conflict of interest The authors declare no conflict of interest.

Ethical Approval All procedures performed in studies involving human participants were in accordance with the ethical standards of the University of Tennessee Institutional Review Board and with the 1964 Helsinki declaration and its later amendments or comparable ethical standards.

Informed Consent Informed consent was obtained from all subjects involved in the study.

\section{References}

Abramson, D. M., Grattan, L. M., Mayer, B., Colten, C. E., Arosemena, F. A., Bedimo-Rung, A., \& Lichtveld, M. (2015). The resilience activation framework: A conceptual model of how access to social resources promotes adaptation and rapid recovery in post-disaster settings. The Journal of Behavioral Health Wervices \&amp; Research, 42(1), 42-57.

Ahmad, S., Feder, A., Lee, E. J., Wang, Y., Southwick, S. M., Schlackman, E., Buchholz, K., Alonso, A., \& Charney, D. S. (2010). Earthquake impact in a remote South Asian population: Psychosocial factors and posttraumatic symptoms. Journal of Traumatic Stress, 23(3), 408-413.

Aldrich, D. P., \& Meyer, M. A. (2015). Social capital and community resilience. American Behavioral Scientist, 59(2), 254-269. https:// doi.org/10.1177/0002764214550299

Ashcroft, R., McMillan, C., Ambrose-Miller, W., McKee, R., \& Brown, J. B. (2018). The emerging role of social work in primary health care: A survey of social workers in Ontario Family Health Teams. Health \&amp; Social Work, 43(2), 109-117.

Bauwens, J., \& Naturale, A. (2017). The role of social work in the aftermath of disasters and traumatic events. Clinical Social Work Journal, 45(2), 99-101. https://doi.org/10.1007/s10615-017-0623-8

Bistricky, S. L., Long, L. J., Lai, B. S., Gallagher, M. W., Kanenberg, H., Elkins, S. R., Harper, K. L., \& Short, M. B. (2019). Surviving the storm: Avoidant coping, helping behavior, resilience and affective symptoms around a major hurricane-flood. Journal of Affective Disorders, 257, 297-306. https://doi.org/10.1016/j.jad. 2019.07.044

Blevins, C. A., Weathers, F. W., Davis, M. T., Witte, T. K., \& Domino, J. L. (2015). The posttraumatic stress disorder checklist for DSM-5 (PCL-5): Development and initial psychometric evaluation. Journal of Traumatic Stress, 28(6), 489-498. https://doi.org/ $10.1002 /$ jts. 22059

Bonanno, G. A. (2004). Loss, trauma, and human resilience: Have we underestimated the human capacity to thrive after extremely aversive events? American Psychologist, 59, 20-28. https://doi. org/10.1037/0003-066X.59.1.20

Bonanno, G. A., Galea, S., Bucciarelli, A., \& Vlahov, D. (2006). Psychological resilience after disaster: New York city in the aftermath of the september 11th terrorist attack. Psychological Science, 17(3), 181-186.

Brewin, C. R., Andrews, B., \& Valentine, J. D. (2000). Meta-analysis of risk factors for posttraumatic stress disorder in trauma-exposed adults. Journal of Consulting and Clinical Psychology, 68(5), 748-766.

Cham, H., Reshetnyak, E., Rosenfeld, B., \& Breitbart, W. (2017). Full information maximum likelihood estimation for latent variable interactions with incomplete indicators. Multivariate Behavioral Research, 52(1), 12-30. https://doi.org/10.1080/00273171.2016. 1245600

Demuth, J. L. (2018). Explicating experience: Development of a valid scale of past hazard experience for tornadoes. Risk Analysis, 38(9), 1921-1943. https://doi.org/10.1111/risa.12983

Du, J., Dong, L., Wang, T., Yuan, C., Fu, R., Zhang, L., Liu, B., Zhang, M., Yin, Y., Qin, J., Bouey, J., Zhao, M., \& Li, X. (2020). Psychological symptoms among frontline healthcare workers during COVID-19 outbreak in Wuhan. General Hospital Psychiatry. https://doi.org/10.1016/j.genhosppsych.2020.03.011

Ferreira, R. J., Adolph, V., Hall, M., \& Buttell, F. (2019). Predictors of individual resilience: Gender differences among African Americans. Journal of Evidence-Based Social Work, 16(4), 347-362.

First, J. M., Shin, H., Ranjit, Y. S., \& Houston, J. B. (2020). COVID-19 stress and depression: Examining social media, traditional media, and interpersonal communication. Journal of Loss and Trauma. https://doi.org/10.1080/15325024.2020.1835386

First, J. M., Yu, M., \& Houston, J. B. (2021). The disaster adaptation and resilience scale: Development and validation of an individuallevel protection measure. Disasters, 45(4), 939-967. https://doi. org/10.1111/disa. 12452

Fullerton, C. S., Ursano, R. J., Liu, X., McKibben, J. B. A., Wang, L., \& Reissman, D. B. (2015). Depressive symptom severity and community collective efficacy following the 2004 Florida Hurricanes. PLoS ONE, 10(6), e0130863. https://doi.org/10.1371/ journal.pone. 0130863

Garfin, D. R., Holman, E. A., \& Silver, R. C. (2015). Cumulative exposure to prior collective trauma and acute stress responses to the Boston marathon bombings. Psychological Science, 26(6), 675-683. https://doi.org/10.1177/0956797614561043

Gelkopf, M., Berger, R., Bleich, A., \& Silver, R. C. (2012). Protective factors and predictors of vulnerability to chronic stress: A comparative study of 4 communities after 7 years of continuous rocket fire. Social Science and Medicine, 74(5), 757-766. https:// doi.org/10.1016/j.socscimed.2011.10.022 
Harville, E. W., Shankar, A., Schetter, C. D., \& Lichtveld. (2017). Cumulative effects of the Gulf oil spill and other disasters on mental health among reproductive-aged women: The Gulf Resilience on Women's Health Study. Psychological Trauma: Theory, Research, Practice, and Policy. https://doi.org/10.1037/tra00 00345.supp

Hobfoll, S. E., Stevens, N. R., \& Zalta, A. K. (2015). Expanding the science of resilience: Conserving resources in the aid of adaptation. Psychological Inquiry, 26(2), 174-180. https://doi.org/10. 1080/1047840X.2015.1002377

Houston, J. B., Spialek, M. L., First, J., Stevens, J., \& First, N. L. (2017). Individual perceptions of community resilience following the 2011 Joplin tornado. Journal of Contingencies and Crisis Management. https://doi.org/10.1111/1468-5973.12171

Houston, J. B., Spialek, M. L., Stevens, J., First, J., Mieseler, V. L., \& Pfefferbaum, B. (2015). 2011 Joplin, Missouri tornado experience, mental health reactions, and service utilization: Cross-sectional assessments at approximately 6 months and 2.5 years post-event. PLoS Currents. https://doi.org/10.1371/currents.dis.18ca227647 291525ce3415bec1406aa5

Irmansyah, I., Dharmono, S., Maramis, A., \& Minas, H. (2010). Determinants of psychological morbidity in survivors of the earthquake and tsunami in Aceh and Nias. International Journal of Mental Health Systems, 4(1), 8. https://doi.org/10.1186/1752-4458-4-8

Jacobs, M. B., \& Harville, E. W. (2015). Long-term mental health among low-income, minority women following exposure to multiple natural disasters in early and late adolescence compared to adulthood. Child \&amp; Youth Care Forum, 44, 511-525. https:// doi.org/10.1007/s10566-015-9311-4

Kira, I. A., Shuwiekh, H. A. M., Rice, K. G., Ashby, J. S., Elwakeel, S. A., Sous, M. S. F., Alhuwailah, A., Baali, S. B. A., Azdaou, C., Oliemat, E. M., \& Jamil, H. J. (2020). Measuring COVID-19 as traumatic stress: Initial psychometrics and validation. Journal of Loss and Trauma. https://doi.org/10.1080/15325024.2020.17901 60

Kline, R. B. (2015). Principles and practice of structural equation modeling (3rd ed.). Guilford Publications.

Kroenke, K., Spitzer, R. L., \& Williams, J. B. (2001). The PHQ-9: Validity of a brief depression severity measure. Journal of General Internal Medicine, 16(9), 606-613. https://doi.org/10.1046/j. 1525-1497.2001.016009606.x

Little, T. D. (2013). Longitudinal structural equation modeling. Guilford Press.

Long, L. J., Bistricky, S. L., Phillips, C. A., D’Souza, J. M., Richardson, A. L., Lai, B. S., Short, M., \& Gallagher, M. W. (2020). The potential unique impacts of hope and resilience on mental health and well-being in the wake of hurricane Harvey. Journal of Traumatic Stress, 33(6), 962-972. https://doi.org/10.1002/jts.22555

Lowe, S. R., McGrath, J. A., Young, M. N., Kwok, R. K., Engel, L. S., Galea, S., \& Sandler, D. P. (2019). cumulative disaster exposure and mental and physical health symptoms among a large sample of gulf coast residents. Journal of Traumatic Stress, 32(2), 196-205. https://doi.org/10.1002/jts.22392

Lowe, S. R., Sampson, L., Gruebner, O., \& Galea, S. (2015). Psychological resilience after Hurricane Sandy: The influence of individual- and community-level factors on mental health after a large-scale natural disaster. PLOS ONE, 10(5), e0125761. https:// doi.org/10.1371/journal.pone.0125761

Luthar, S. S., Cicchetti, D., \& Becker, B. (2000). The construct of resilience: A critical evaluation and guidelines for future work. Child Development, 71, 543-562.

Masten, A. S. (2001). Ordinary magic: Resilience processes in development. American Psychologist, 56(3), 227-238.

Masten, A. S., \& Motti-Stefanidi, F. (2020). Multisystem resilience for children and youth in disaster: Reflections in the context of
COVID-19. Adversity and Resilience Science. https://doi.org/10. 1007/s42844-020-00010-w

Masten, A. S., \& Obradovic, J. (2008). Disaster preparation and recovery: Lessons from research on resilience in human development. Ecology and Society, 13(1), 9.

Maxwell, S. E., \& Cole, D. A. (2007). Bias in cross-sectional analyses of longitudinal mediation. Psychological Methods, 12(1), 23-44. https://doi.org/10.1037/1082-989X.12.1.23

Neria, Y., Nandi, A., \& Galea, S. (2008). Post-traumatic stress disorder following disasters: A systematic review. Psychological Medicine, 38(4), 467-480. https://doi.org/10.1017/S003329170 7001353

Norris, F. H., Friedman, M. J., Watson, P. J., Byrne, C. M., Diaz, E., \& Kaniasty, K. (2002). 60,000 disaster victims speak: Part I. An empirical review of the empirical literature, 1981-2001. Psychiatry, 65(3), 207-239. https://doi.org/10.1521/psyc.65.3.207.20173

Norris, F. H., Stevens, S. P., Pfefferbaum, B., Wyche, K. F., \& Pfefferbaum, R. L. (2008). Community resilience as a metaphor, theory, set of capacities, and strategy for disaster readiness. American Journal of Community Psychology, 41(1), 127-150.

Osofsky, H. J., Osofsky, J. D., \& Hansel, T. C. (2011). Deepwater horizon oil spill: Mental health effects on residents in heavily affected areas. Disaster Medicine Public Health Preparedness, 5(4), 280-286. https://doi.org/10.1001/dmp.2011.85

Pfefferbaum, R. L., et al. (2013). The communities advancing resilience toolkit (CART): Development of a survey instrument to assess community resilience. International Journal of Emergency Mental Health and Human Resilience, 15(1), 15-30.

Pfefferbaum, R. L., Pfefferbaum, B., Nitiéma, P., Houston, J. B., \& Van Horn, R. L. (2015). Assessing community resilience: An application of the expanded CART survey instrument with affiliated volunteer responders. American Behavioral Scientist, 59(2), 181-199. https://doi.org/10.1177/0002764214550295

Preacher, K. J., \& Hayes, A. F. (2008). Contemporary approaches to assessing mediation in communication research. In A. F. Hayes, M. D. Slater, \& L. B. Snyder (Eds.), The Sage sourcebook of advanced data analysis methods for communication research (pp. 13-54). Sage Publications.

R Core Team. (2011). R: A language and environment for statistical computing. R Foundation for Statistical Computing, Vienna, Austria. Retrieved from http://www.R-project.org/

Roach, J. (2020). AccuWeather estimates the total damage from the Tennessee tornadoes will approach \$2 billion. Retrieved from https://www.accuweather.com/en/severe-weather/accuweatherestimates-the-total-damage-from-the-tennessee-tornadoes-willapproach-2-billion/697185

Southwick, S. M., Bonanno, G. A., Masten, A. S., Panter-Brick, C., \& Yehuda, R. (2014). Resilience definitions, theory, and challenges: Interdisciplinary perspectives. European Journal of Psychotraumatology. https://doi.org/10.3402/ejpt.v5.25338

Stanglin, D., Whitney, A. L., \& Estes, G. (2020, March). 'Pretty much like an explosion': Day after brutal Nashville tornadoes that killed 25 people, 3 still missing. Retrieved from USA Today https://www.usatoday.com/story/news/nation/2020/03/04/nashv ille-tornado-2020-at-least-24-dead/4950680002/

Tennessee Department of Health. (2021). Retrieved from https://www. tn.gov/health/cedep/ncov.html

Ungar, M., Ghazinour, M., \& Richter, J. (2013). Annual Research Review: What is resilience within the social ecology of human development? Journal of Child Psychology and Psychiatry, 54(4), 348-366. https://doi.org/10.1111/jcpp.12025

Veldhuis, C. B., Nesoff, E. D., McKowen, A., Rice, D. R., Ghoneima, H., Wootton, A. R., Papautsky, E. L., Arigo, D., Goldberg, S., \& Anderson, J. C. (2021). Addressing the critical need for long-term mental health data during the COVID-19 pandemic: Changes in 
mental health from April to September 2020. Preventive Medicine, 146, 106465. https://doi.org/10.1016/j.ypmed.2021.106465

Walter-McCabe, H. A. (2020). Coronavirus pandemic calls for an immediate social work response. Social Work in Public Health, 35(3), 69-72.

Wind, T. R., \& Komproe, I. H. (2012). The mechanisms that associate community social capital with post-disaster mental health: A multilevel model. Social Science \&amp; Medicine (1892), 75(9), 1715-1720. https://doi.org/10.1016/j.socscimed.2012.06.032

Windle, G., Bennett, K. M., \& Noyes, J. (2011). A methodological review of resilience measurement scales. Health and Quality of Life Outcomes, 9(1), 8. https://doi.org/10.1186/1477-7525-9-8

Wu, M., Xu, W., Yao, Y., Zhang, L., Guo, L., Fan, J., \& Chen, J. (2020). Mental health status of students' parents during COVID19 pandemic and its influence factors. General Psychiatry, 33(4), e100250. https://doi.org/10.1136/gpsych-2020-100250

Ying, L., Wu, X., Lin, C., \& Jiang, L. (2014). Traumatic severity and trait resilience as predictors of posttraumatic stress disorder and depressive symptoms among adolescent survivors of the Wenchuan earthquake. PLoS ONE, 9(2), e89401. https://doi.org/10. 1371/journal.pone.0089401
Publisher's Note Springer Nature remains neutral with regard to jurisdictional claims in published maps and institutional affiliations.

Jennifer M. First PhD, MSW, is Assistant Professor in the College of Social Work at the University of Tennessee, Knoxville and Faculty Fellow in the Disaster and Community Crisis Center at the University of Missouri. Her research focuses on human experiences with disaster events and the consequences of collective trauma.

J. Brian Houston $\mathrm{PhD}$, is Associate Professor and Chair in the Department of Communication and is Director for the Disaster and Community Crisis Center at the University of Missouri. Houston's research focuses on communication at all phases of disasters and on the mental health effects of community crises. 